\title{
ANALYSIS OF RIGHT VENTRICULAR FUNCTION DURING BYPASS OF THE LEFT SIDE OF THE HEART BY AFTERLOAD ALTERATIONS IN BOTH NORMAL AND FAILING HEARTS
}

Chang-Hee Park, MD

Kazunobu Nishimura, MD, PhD

Mitsuru Kitano, MD

Katsuhiko Matsuda, MD, $\mathrm{PhD}$

Yoshifumi Okamoto, MD, PhD

Toshihiko Ban, MD, PhD
This study investigated the mechanism of right ventricular failure during bypass of the left side of the heart by precisely assessing right ventricular function with use of a conductance catheter. Bypass of the left side of the heart was established with a centrifugal pump in 10 mongrel dogs weighing 11 to $19 \mathrm{~kg}$. Right ventricular function during left heart bypass was evaluated by two parameters that were both derived from measurement of relative change in right ventricular volume by the conductance catheter technique. One parameter was the right ventricular end-systolic pressurevolume relationship as a load-independent index, and the other was the peak right ventricular pressure-right ventricular stroke volume relationship as a "force-velocity relationship." These parameters were measured in both normal and failing hearts while afterload was increased by bilateral intrapulmonary balloon inflation. Moreover, changes in these relationships were observed by varying assist ratios of left heart bypass from $0 \%$ to $100 \%$. Failing heart models were induced by normothermic aortic clamping for 20 minutes. The right ventricular end-systolic pressure-volume relationship in normal hearts did not change, irrespective of the assist ratio of left heart bypass, whereas that in failing hearts decreased from $4.25 \pm 1.41 \mathrm{~mm}$ $\mathrm{Hg} / \mathrm{ml}$ without bypass of the left side of the heart to $3.53 \pm 1.30 \mathrm{~mm} \mathrm{Hg} / \mathrm{ml}$ after $100 \%$ assist of left heart bypass $(p<0.05)$. In the peak right ventricular pressure-right ventricular stroke volume relationship, right ventricular stroke volume was almost constant in normal hearts when afterload was increased regardless of the assist ratio of left heart bypass. Moreover, right ventricular stroke volume was maintained at a higher level during bypass of the left side of the heart compared with that without left heart bypass. However, that slope of the relationship in failing hearts was inversely linear and became significantly steeper after $100 \%$ assist of bypass of the left side of the heart compared with that without left heart bypass $(-0.131 \pm 0.042$ versus $-0.051 \pm 0.038, p<0.005)$. Therefore these two slopes of the relationship intersected at a point that was considered the critical point of afterload during bypass of the left side of the heart. In other words, right ventricular stroke volume was decreased by $100 \%$ left heart bypass above the critical point of afterload. In conclusion, this study demonstrates not only that bypass of the left side of the heart results in an increase in right ventricular stroke volume in both normal and failing hearts at the physiologic range of afterload, but also that right ventricular function against higher afterload is impaired by $100 \%$ assist of bypass of the left side of the heart in failing hearts. (J Thorac Cardiovasc Surg 1996; 111:1092-1102)
From the Department of Cardiovascular Surgery, Kyoto University Faculty of Medicine, Kyoto, Japan.

Received for publication April 11, 1995; accepted for publication July 26,1995
Address for reprints: Chang-Hee Park, MD, Department of Cardiovascular Surgery, Kyoto University Faculty of Medicine, 54, Kawara-cho, Shogoin, Sakyo-ku, Kyoto 606, Japan. Copyright (C) 1996 by Mosby-Year Book, Inc. $0022-5223 / 96 \$ 5.00+0 \quad \mathbf{1 2 / 1 / 6 8 2 2 9}$ 
Volume 111, Number 5

$\mathrm{R}_{\mathrm{b}}^{\mathrm{i}}$ ght ventricular (RV) failure during isolated bypass of the left side of the heart (LHB) is a controversial problem that has not yet been resolved, although RV failure has been one of the most important predictors that determine the prognosis of patients with $\mathrm{LHB}^{1-8}$ According to previous clinical reports, $\mathrm{RV}$ failure developed in approximately $20 \%$ to $25 \%$ of patients supported with LHB. ${ }^{1-8}$ Therefore it is important to clarify the mechanism of RV failure and to know how to cope with uncontrollable RV failure.

Although a number of previous studies have improved the understanding of RV physiologic processes during isolated $\mathrm{LHB},{ }^{9-19}$ there are limitations in the methods of determining $\mathrm{RV}$ volume because of the complexity of RV geometry, which causes difficulty in precisely assessing $\mathrm{RV}$ performance and clarifying the mechanism of RV failure during LHB. Some reports showed impairment of RV function during $\mathrm{LHB},{ }^{9,11-15}$ whereas other reports showed no change in RV function during LHB. ${ }^{10,16}$ These conflicting results about RV function during LHB can be explained mainly by the various experimental models and methods used to assess RV contractility and RV volume. Therefore previous reports have not fully clarified the mechanism of clinically significant RV failure during LHB.

In this study, a conductance catheter ${ }^{20,21}$ was applied to determine relative change in instantaneous RV volume in individual cases, and the effects of LHB on RV function were thereby assessed by two descriptors of systolic performance during afterload alterations, in addition to conventional hemodynamic variables. One descriptor was RV endsystolic pressure-volume relationship (ESPVR) as a load independent index. ${ }^{22-24}$ The other was the peak RV pressure (PRVP) to RV stroke volume (RVSV) relationship as a "force-velocity" relationship in cardiac physiology. ${ }^{25}$ Moreover, we produced a failing heart model by simple anoxic clamping of the ascending aorta ${ }^{26}$ and used this model to assess $\mathrm{RV}$ failure during LHB, in addition to using the normal heart model. This study evaluated RV function during LHB and investigated the mechanism of RV failure during LHB by assessing changes in the relationships described.

\section{Methods}

Animal preparation. Ten mongrel dogs weighing 11 to $19 \mathrm{~kg}$ were used in this study. These dogs were anesthetized with ketamine $(10 \mathrm{mg} / \mathrm{kg}$ intramuscularly) and pentobarbital sodium ( $20 \mathrm{mg} / \mathrm{kg}$ intravenously). After endo- tracheal intubation was instituted, anesthesia was maintained with a continuous infusion of pentobarbital sodium and ventilation of the lungs was maintained with an anesthesia respirator (model-B3, Igarashi Inc., Tokyo, Japan). After a left thoracotomy was done at the fourth intercostal space, the pericardium was opened and the heart was exposed. The animal was then given heparin ( 3 $\mathrm{mg} / \mathrm{kg}$ ). LHB was established with a centrifugal pump (model BP-80, BioMedicus, Inc., Eden Prairie, Minn.). A return cannula $(18 \mathrm{~F})$ was inserted into the left subclavian artery and withdrawal cannulas were inserted into the left atrium $(24 \mathrm{~F})$ through the appendage and into the left ventricle $(18 \mathrm{~F})$ through the apex to obtain sufficient left ventricular unloading. Fig. 1 shows a schematic drawing of the experimental preparation including the institution of LHB.

Failing heart models were induced by normothermic aortic clamping for 20 minutes. ${ }^{26}$ During aortic clamping, LHB was established in full assist ratio to preserve organ function.

Monitoring. RV pressure was measured with a catheter-tipped manometer (5F, model TCP2, TOYODA, Inc., Aichi, Japan). Left ventricular pressure and aortic pressure were measured with standard fluid-filled catheters. An electromagnetic flow probe (model MF27, Nihon Kohden Corp., Tokyo, Japan) was placed around the main pulmonary artery to measure pulmonary artery flow.

A $5 \mathrm{~F}$ conductance catheter equipped with eight electrodes spaced at $8 \mathrm{~mm}$ intervals (Cordis, Europa NV, Roden, The Netherlands) was introduced into the RV through the main pulmonary artery in a retrograde manner. The conductance catheter was connected to a volumetric system (Sigma-5, Leycom, Octstgeest, The Netherlands), which continuously produced instantaneous analog RV volume signals. The signals were digitized with an on-line analog-to-digital converter at a sampling rate of $333 \mathrm{~Hz}$ combined with a signal from the manometertipped catheter to obtain the RV pressure-volume relationship and stored on a floppy disk memory system with a computer (model PC-9801RX, NEC, Tokyo, Japan). The position of the catheter in the $R V$, with the most distal electrode placed near the apex and the most proximal electrode just cephalad to the pulmonary valve, was determined by the monitor findings that showed five consecutive segmental pressure-volume loops during the experiments and was finally confirmed on postmortem examination.

Two 7F Fogarty balloon catheters (Baxter Healthcare Corp., Oakland, Calif.) were inserted into the bilateral pulmonary arteries through the main pulmonary artery, and a transient change in RV afterload was obtained by inflating the balloon catheters.

Protocol and data analysis. Hemodynamic variables measured with the conductance catheter technique were defined as follows.

The slope of $R V$ ESPVR. The point of maximal pressure-volume ratio was determined in each cardiac cycle. A least-squared linear regression was first applied to determine the slope of RV ESPVR and intercept V0, where V0 is the volume axis intercept of ESPVR. With this V0 estimate, the points of maximal pressure-volume ratio to $\mathrm{V} 0$ for each cycle were obtained, and a second regression 


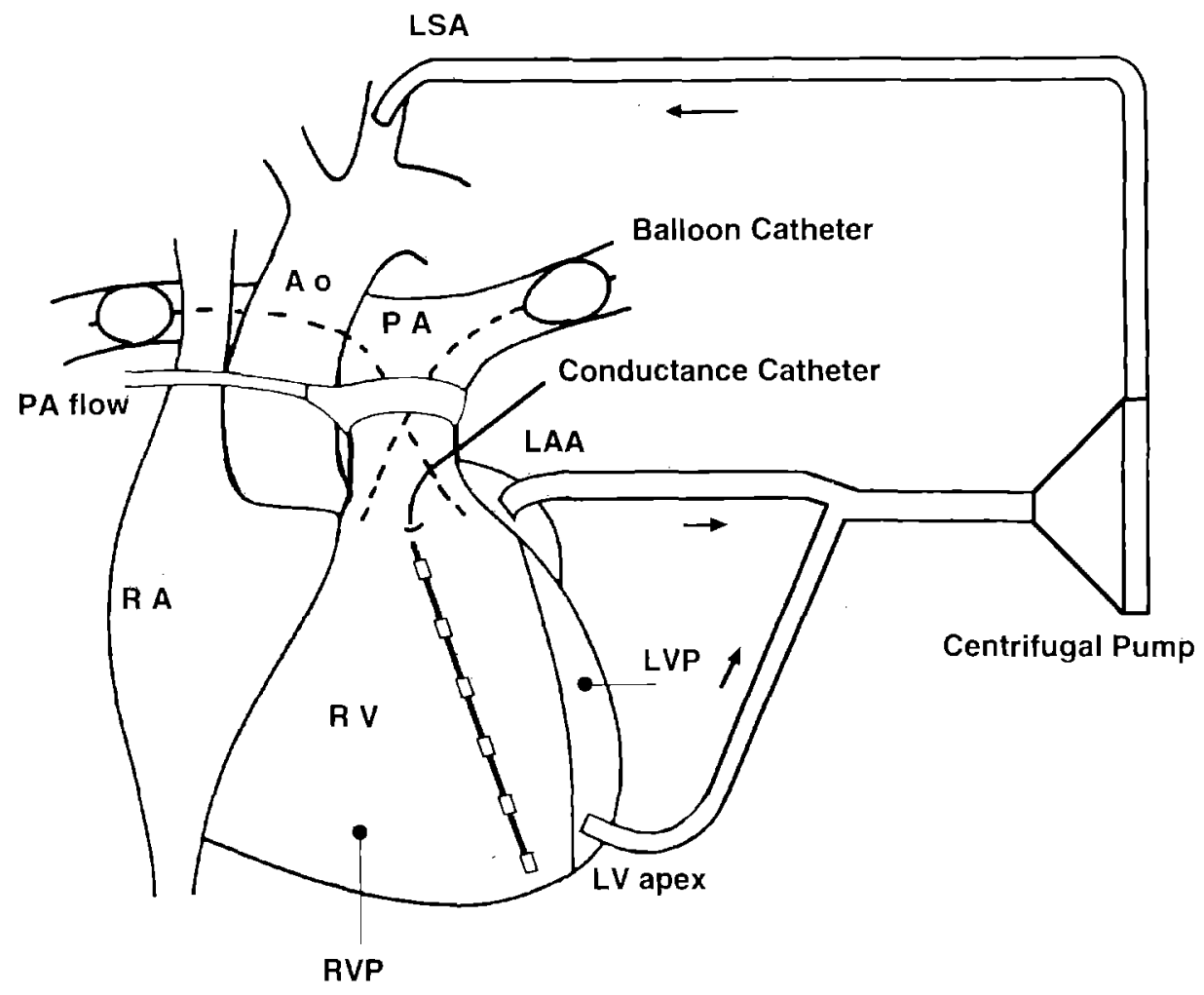

Fig. 1. Schematic diagram of experimental preparation. See text for details. $A o$, Aorta; $P A$, pulmonary artery; $R A$, right atrium; $L S A$, left subclavian artery; $L A A$, left atrial appendage; $L V$ apex, left ventricular apex; $L V P$, left ventricular pressure; $R V P$, RV pressure.

was used to determine new estimates for ESPVR and V0. This process was continued until there was no further change in either parameter estimate with subsequent iterations. $^{27}$

The effective $R V$ end-diastolic volume. Once V0 was determined in the normal heart; the effective RV enddiastolic volume (eRVEDV) was calculated by the following equation ${ }^{15}$ : eRVEDV $=$ RVEDV (actual value measured by conductance catheter) - V0 (in the normal heart).

$R V S V$. RVSV was the maximal volume minus the minimal volume (in each cardiac cycle).

$R V$ ejection fraction. RV ejection fraction was determined as RVSV divided by eRVEDV.

PRVP to RVSV relationship. RVSV was determined by the stated formula at various PRVPs induced by inflating two balloon catheters, and a linear regression of the correlation between PRVP and RVSV was determined as the slope of the PRVP-RVSV relationship.

To evaluate the effects of LHB on RV function, RV ESPVR and the PRVP-RVSV relationship were assessed during $\mathrm{LHB}$ with the assist ratio varied from $0 \%$ to $100 \%$ $(0 \%, 50 \%, 75 \%, 100 \%)$. The assist flow ratio was determined as LHB flow (in liters per minute) divided by pulmonary arterial flow (in liters per minute). After baseline measurement of the pressure-volume loop was obtained, RV pressure was raised by inflating the balloon catheters so that serial RV pressure-volume loops were obtained to determine the RV ESPVR and PRVP-RVSV relationship. All these hemodynamic variables were measured in both normal and failing hearts. All measurements were taken immediately after the dog was disconnected from ventilatory support to sustain end expiration. The hemodynamic measurements without LHB in failing hearts were collected again after each experiment to ascertain that the conditions of failing hearts were unchanged compared with those before all measurements in failing hearts. In failing hearts, collection of the data required about 10 minutes.

All animals received humane care in compliance with the "Principles of Laboratory Animal Care" formulated by the National Society for Medical Research and the "Guide for the Care and Use of Laboratory Animals" prepared by the National Academy of Sciences and published by the National Institutes of Health (NIH Publication No. 86-23, revised 1985).

All values are presented as means plus or minus one standard deviation. To evaluate the change in hemodynamic variables as described earlier, the values obtained at each assist ratio of LHB were compared in individual animals. The Friedman test was used to analyze the mean values of hemodynamic variables derived from the conductance catheter technique at each assist ratio. If any significant group effect was detected by the Friedman test, 


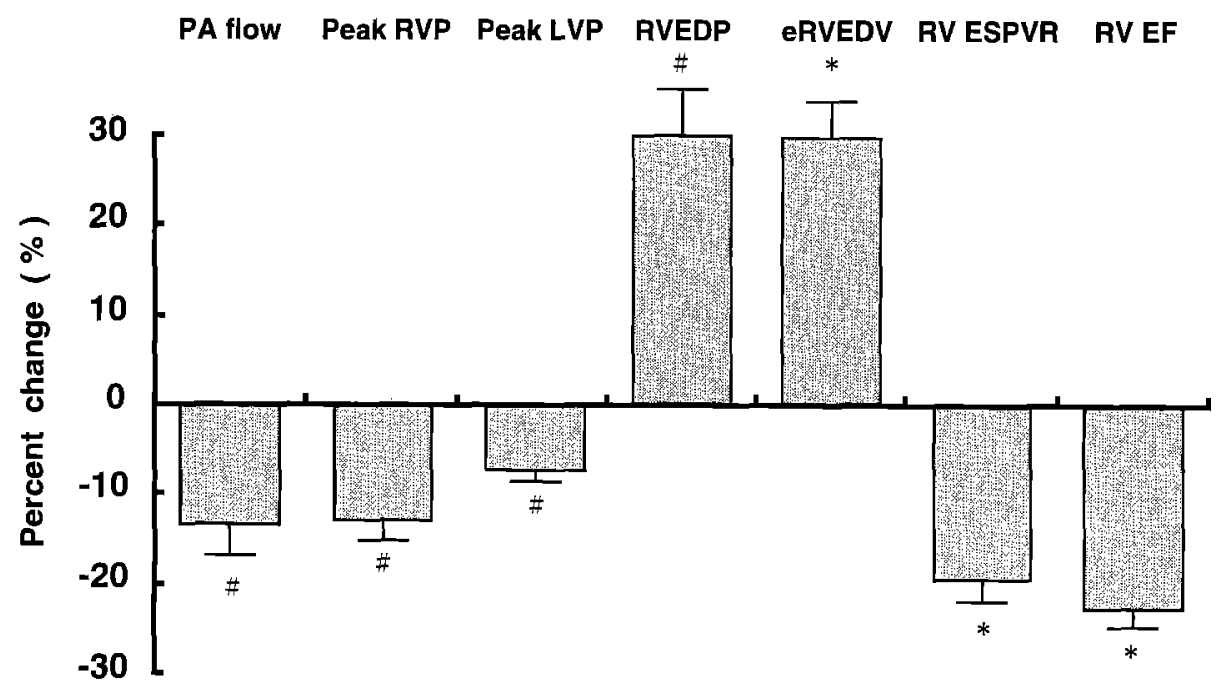

Fig. 2. Percent change of hemodynamic variables after failing heart models were induced. $P A$ flow, Pulmonary artery flow; $L V P$, left ventricular pressure; $R V E D P, \mathrm{RV}$ end-diastolic pressure; $E F$, ejection fraction. ${ }^{*} p<0.05$ by Wilcoxon signed-rank test compared with value in normal hearts. ${ }^{*} p<0.05$ by paired $t$ test compared with value in normal hearts.

the Wilcoxon signed-rank test was used to determine the significance of differences between groups. Other hemodynamic variables were analyzed by paired $t$ test and analysis of variance if necessary. A $p$ value less than 0.05 was considered significant.

\section{Results}

Characterization of the failing heart model. Fig. 2 summarizes changes in the hemodynamic variables from 10 mongrel dogs with heart failure compared with variables before heart failure was induced. Pulmonary artery flow measured by an electromagnetic flow probe was significantly decreased by 15.6\%. PRVP and peak left ventricular pressure were also decreased significantly by $12.1 \%$ and $7.5 \%$, respectively. RV end-diastolic pressure was significantly increased by $30.0 \%$. Moreover, as a consequence of measuring RV contractile parameters derived from the conductance catheter, eRVEDV in the failing hearts increased significantly by $29.9 \%$, whereas RV ESPVR and RV ejection fraction decreased significantly by $19.7 \%$ and $22.9 \%$, respectively.

Effect of $100 \%$ assist of LHB on RV global function. Table I shows hemodynamic variables during $100 \%$ assist of LHB compared with those without LHB in both normal and failing hearts. Because full drainage of blood from the left ventricle and the left atrial appendage was attempted, peak left ventricular pressure was significantly reduced. Full drainage from the left side of the heart, in both normal and failing hearts, resulted in a significant increase in eRVEDV and significant decrease in PRVP. However, RV ejection fraction did not change during $100 \%$ assist of LHB compared with that without LHB. These values might have contributed to a significant increase in pulmonary artery flow. Consequently, $100 \%$ assist of $\mathrm{LHB}$ resulted in a net improvement of $\mathrm{RV}$ function in both normal and failing hearts.

Effect of LHB on RV ESPVR. Table II summarizes the change in RV ESPVR in association with eRVEDV and peak left ventricular pressure in both normal and failing hearts when the assist ratio of LHB was varied. In proportion to increases in the assist ratio of LHB, eRVEDV gradually increased, whereas peak left ventricular pressure decreased in both normal and failing hearts. However, in normal hearts, the slope of RV ESPVR did not change, irrespective of the assist ratio of LHB. By contrast, in failing hearts, the slope of RV ESPVR decreased significantly with increases in the assist ratio of LHB. Fig. 3 shows representative RV pressurevolume loops obtained in normal hearts, which demonstrated the parallel rightward shift of the slope of the RV ESPVR during 100\% assist of LHB. Fig. 4 shows representative RV pressure-volume loops obtained in failing hearts, which demonstrated the decrease in RV ESPVR with increases in the assist ratio of LHB. 
Table I. Effect of $100 \%$ assist of LHB on RV global function in both normal and failing hearts

\begin{tabular}{|c|c|c|c|c|}
\hline & \multicolumn{2}{|c|}{ Normal hearts } & \multicolumn{2}{|c|}{ Failing hearts } \\
\hline & Without LHB & $100 \% L H B$ & Without LHB & $100 \% \mathrm{LHB}$ \\
\hline Peak LVP (mm Hg) & $110.8 \pm 5.9$ & $12.9 \pm 5.8^{*}$ & $102.5 \pm 5.8$ & $10.8 \pm 2.6^{*}$ \\
\hline eRVEDV (ml) & $6.73 \pm 1.57$ & $7.83 \pm 1.62 \uparrow$ & $8.74 \pm 2.41$ & $10.54 \pm 2.42 \dagger$ \\
\hline PRVP (mm Hg) & $24.0 \pm 3.5$ & $21.0 \pm 3.8^{*}$ & $21.1 \pm 2.8$ & $17.2 \pm 2.9^{*}$ \\
\hline $\mathrm{EF}(\%)$ & $61.6 \pm 5.6$ & $61.0 \pm 5.3$ & $47.5 \pm 6.6$ & $49.5 \pm 7.2$ \\
\hline PA flow ( $\mathrm{L} / \mathrm{min})$ & $1.25 \pm 0.36$ & $1.42 \pm 0.33^{*}$ & $1.08 \pm 0.3$ & $1.24 \pm 0.25^{*}$ \\
\hline
\end{tabular}

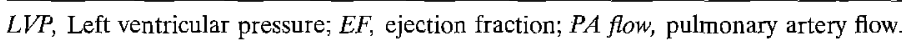

${ }^{*} p<0.05$ by paired $t$ test compared with value without LHB.

$\dagger p<0.05$ by Wilcoxon signed-rank test compared with value without LHB,

Table II. Change in RV ESPVR with increase in assist ratio of $L H B$ in both normal and failing hearts

\begin{tabular}{lcccc} 
& $0 \%$ & $50 \%$ & $70 \%$ & $100 \%$ \\
\hline Normal hearts & & & & \\
RV ESPVR (mm Hg/ml) & $5.29 \pm 1.67$ & $5.24 \pm 1.66$ & $5.21 \pm 1.65$ & $5.24 \pm 1.76$ \\
eRVEDV (ml) & $6.73 \pm 1.57$ & $7.01 \pm 1.61$ & $7.45 \pm 1.58^{*}$ & $7.83 \pm 1.62^{*}$ \\
Peak LVP (mm Hg) & $110.8 \pm 5.9$ & $98.1 \pm 8.9$ & $55.8 \pm 12.1 \dagger$ & $12.9 \pm 5.8 \dagger$ \\
Failing hearts & & & \\
RV ESPVR (mm Hg/ml) & $4.25 \pm 1.41$ & $4.12 \pm 1.40$ & $3.74 \pm 1.45^{*}$ & $3.53 \pm 1.30^{*}$ \\
eRVEDV (ml) & $8.74 \pm 2.41$ & $9.24 \pm 2.20$ & $9.94 \pm 2.18^{*}$ & $10.54 \pm 2.42^{*}$ \\
Peak LVP (mm Hg) & $102.5 \pm 5.8$ & $92.5 \pm 8.3$ & $53.6 \pm 14.3 \dagger$ & $10.8 \pm 2.6 \dagger$ \\
\hline
\end{tabular}

$\overline{L V P}$, Left ventricular pressure.

${ }^{*} p<0.05$ by Wilcoxon signed-rank test compared with valve without LHB.

$\dagger p<0.05$ by paired $t$ test compared with valve without LHB.

Effect of LHB on the PRVP-RVSV relationship. Fig. 5 summarizes the change in the PRVP-RVSV relationship with increases in the assist ratio of LHB in both normal and failing hearts. In normal hearts, there were no changes in the slope of the relationship regardless of the assist ratio of LHB. Moreover, RVSV was maintained at a higher level during LHB compared with that without LHB (Fig. 6). In failing hearts, the correlation between PRVP and RVSV was inversely linear in all cases with a significant regression ( $r$ values from 0.91 to 0.95 ) during increases in PRVP induced by inflation of the balloon catheter. Moreover, in failing hearts, the slope of the correlation became steeper at $100 \%$ assist of LHB compared with that without LHB $(-0.131 \pm$ 0.042 versus $-0.051 \pm 0.038, p<0.005$ ). Because of different correlative slopes, these two slopes intersected as illustrated in Fig. 7, $A$. Moreover, reduction of the assist ratio from $100 \%$ to $70 \%$ caused the slope of the PRVP-RVSV correlation to become significantly more gentle $(70 \%$ LHB, $-0.072 \pm$ 0.037 versus $100 \%$ LHB $,-0.131 \pm 0.042, p<0.05$ ), and thereby the intersection point of afterload at $70 \%$ LHB shifted rightward, which indicated a higher afterload, as illustrated in Fig. 7, B. Consequently, the intersection point at $70 \%$ LHB assist was significantly higher than the level at $100 \%$ LHB assist $(70 \% \mathrm{LHB}, 38.1 \pm 6.9 \mathrm{~mm} \mathrm{Hg}$ versus $100 \%$ $\mathrm{LHB}, 29.2 \pm 6.8 \mathrm{~mm} \mathrm{Hg}, p<0.05)$.

\section{Discussion}

With use of a conductance catheter to determine instantaneous relative change in RV volume, this study showed that LHB resulted in a rightward parallel shift of the slope of the RV ESPVR in normal hearts, whereas RV ESPVR decreased significantly with increases in the assist ratio of LHB in failing hearts. These observations are compatible with the results of the studies of Farrar and associates ${ }^{13}$ and Chow and Farrar ${ }^{14,18}$ in which sonomicrometry was used, which described similar changes in the RV ESPVR in normal and failing hearts. With studies in normal hearts, some reports showed that RV ESPVR did not change during LHB, ${ }^{10,14,16}$ whereas other reports showed the decrease in $\mathrm{RV}$ ESPVR during LHB. ${ }^{15,19}$ Contradiction among these results might be caused by differences in methods used for measuring RV ESPVR or by 
difficulty in assessing subtle changes in the RV ESPVR in normal hearts. The report of Chow and Farrar $^{18}$ was the first that used the failing heart model, and it showed the significant decrease in RV ESPVR during LHB. However, these previous studies have not clarified why RV ESPVR decreased during LHB in failing hearts unlike findings in normal hearts. From our perspective, the mechanism of reduction in RV ESPVR during LHB may be mainly attributed to the increase in RV volume, which subsequently induces an increase in RV wall stress. ${ }^{28}$ As we previously reported, ${ }^{29}$ the change in RV ESPVR showed a significant correlation with the change in RV volume during LHB. This observation suggests that LHB has the potential to cause reduction in the RV ESPVR by increasing $R V$ volume in both normal and failing hearts. This study showed that, in failing hearts, the eRVEDV increased significantly compared with that in normal hearts and increased further after $100 \%$ LHB. Consequently, in failing hearts, LHB resulted in further increase of $R V$ volume that was already increased. Further enlargement of the RV volume in the failing hearts induces additional increases in RV wall stress, which could eventually induce impairment of RV systolic function during LHB unlike that in normal hearts. Therefore, a further increment of RV wall stress during LHB was considered the reason that $\mathrm{LHB}$ resulted in a significant decrease in RV ESPVR in failing hearts.

However, by a reduction in RV ESPVR alone, it is difficult to explain the RV failure during LHB that is encountered clinically. In general, even if RV ESPVR were reduced during LHB, RVSV could increase as a result of not only a decrease in RV afterload but also an increase in RVEDV during LHB. Therefore other factors must be considered to account for the RV failure. Accordingly, the PRVPRVSV relationship was examined to further elucidate the cause of the RV failure in this study because ventricular function could be best assessed by afterload alterations. ${ }^{30,31}$ In the force-velocity relationship in the cardiac physiologic process, ventricular function is inversely correlated with ventricular afterload. ${ }^{25}$ We also demonstrated that RVSV had a significant inverse correlation with PRVP in failing hearts regardless of the assist ratio of LHB. Moreover, the slope of this correlation, in failing hearts, became steeper during $100 \%$ LHB compared with that without LHB, which was not observed in normal hearts. Thus an intersection between the steeper slope induced by $100 \% \mathrm{LHB}$ and
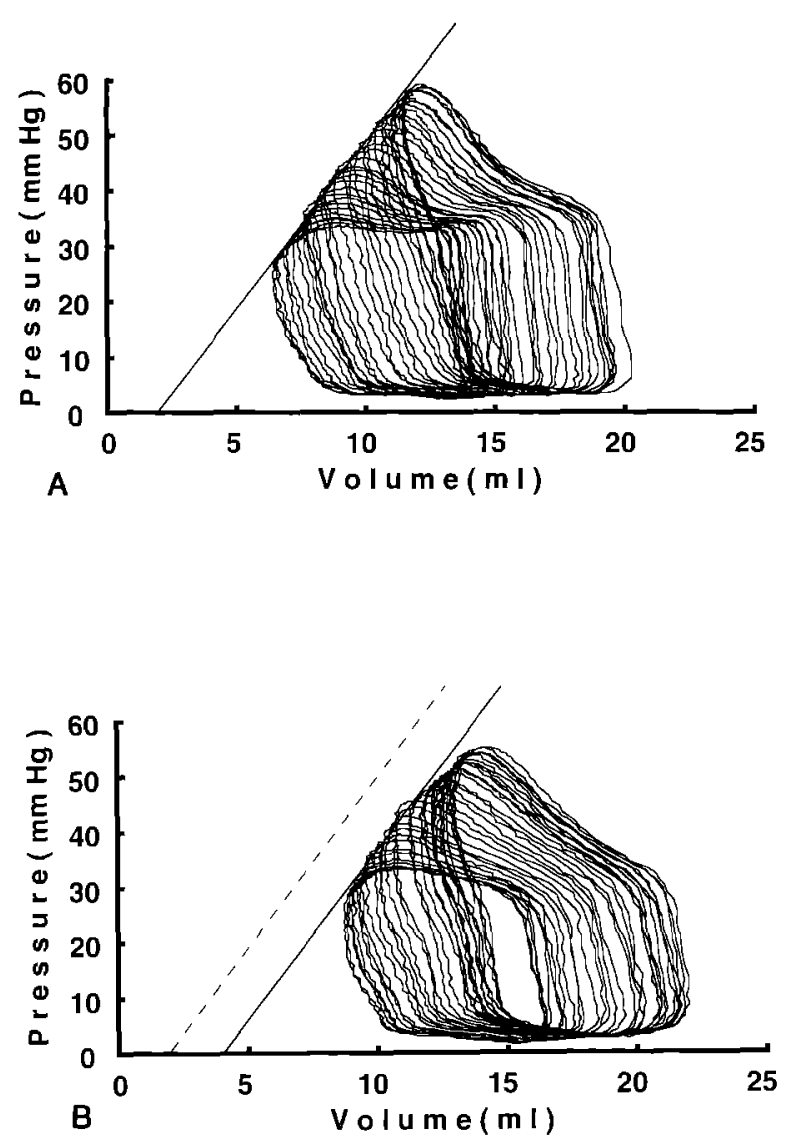

Fig. 3. Representative RV pressure-volume loops obtained in normal hearts. A, Representative RV pressurevolume loops obtained during bilateral intrapulmonary balloon inflation without LHB. Line shows slope of RV ESPVR. B, RV pressure-volume loops obtained with $100 \%$ assist of LHB in normal hearts. Line shows slope of RV ESPVR, Broken line shows slope of RV ESPVR without LHB. One hundred percent assist of LHB resulted in parallel rightward shift of RV ESPVR in normal hearts.

the gentle slope without LHB was noted in failing hearts. This intersection was considered the critical afterload above which RVSV was decreased by LHB compared with that without LHB, indicating that RVSV would decrease during LHB when LHB was driven higher than the critical point of the afterload. The existence of this critical point in failing hearts means that RV function against afterload is impaired by LHB, which may reproduce clinically significant RV failure during LHB. The PRVP-RVSV relationship is, therefore, a useful parameter to exhibit clinical conditions of RV failure during LHB. 

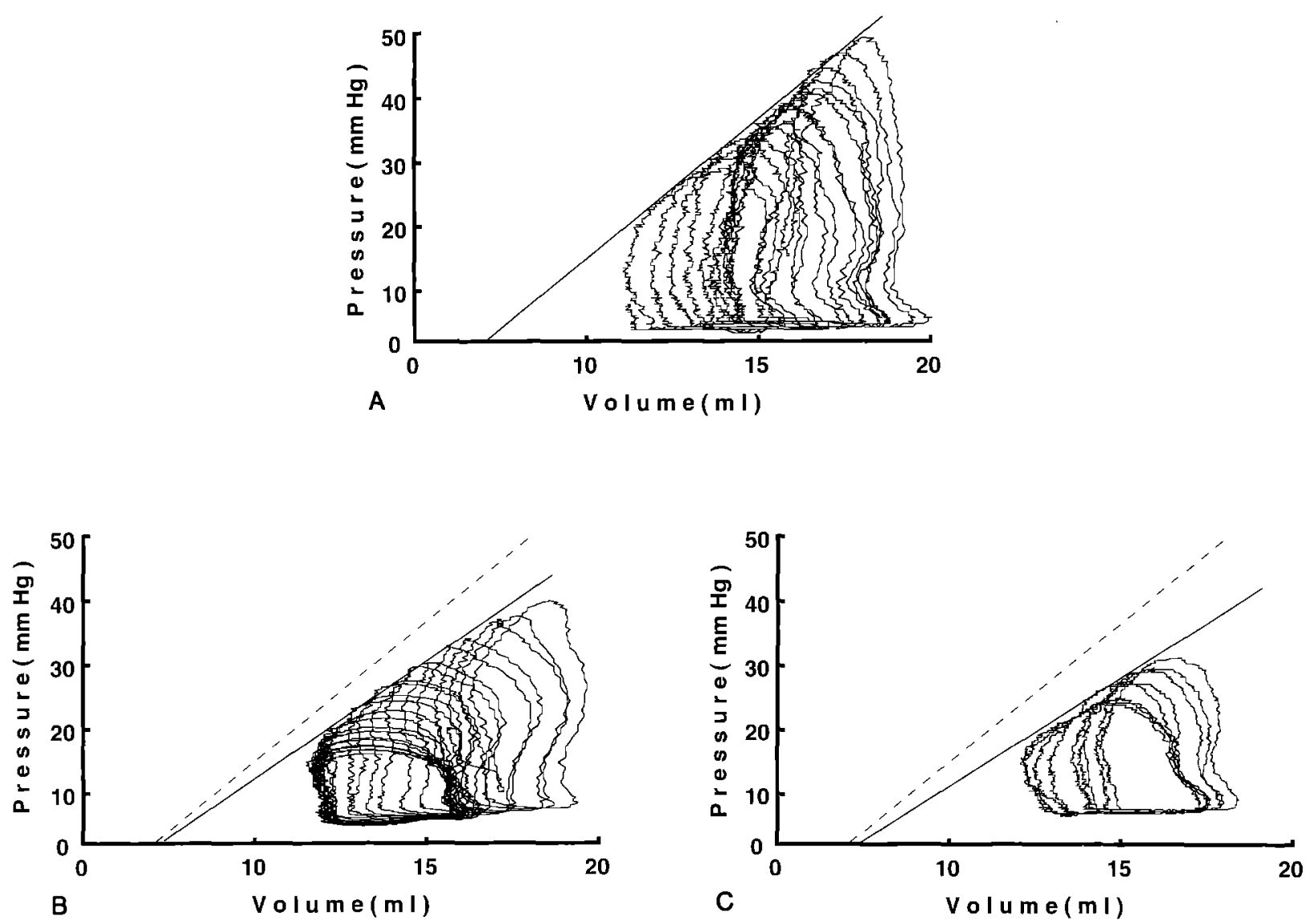

Fig. 4. Representative RV pressure-volume loops obtained in failing hearts. A, Pressure-volume loops without LHB. Line shows slope of RV ESPVR. B, Pressure-volume loops with 70\% assist of LHB. Line shows slope of RV ESPVR with 70\% LHB and broken line shows slope of RV ESPVR without LHB. C, Pressure-volume loops with 100\% assist of LHB. Line shows slope of RV ESPVR with 100\% LHB and broken line shows slope of RV ESPVR without LHB. Consequently, RV ESPVR decreased with increase in assist ratio of LHB in failing hearts.

At levels below the critical point, as a matter of course, $100 \%$ assist of LHB results in a net improvement of RV function both in normal and failing hearts, as shown by this study, because the increase in RVEDV and the reduction in RV afterload by $100 \%$ LHB induce the increase in RVSV, as compared with the result without LHB, which is compatible with the findings of the clinical report of Morita and associates. ${ }^{32}$ It must be emphasized, however, that in failing hearts, the steepest slope in the correlation between PRVP and RVSV indicates that $100 \%$ LHB, which induces increases in RVSV at levels below the critical point, also renders the $\mathrm{RV}$ intolerant of afterload at levels above the critical point. In other words, the detrimental effects of LHB (that is, steeper slope in the relationship between PRVP and RVSV) overcome the beneficial effects of LHB (that is, the reduction in RV afterload and the increase in RVEDV) above the critical point, resulting in the decrease in RVSV, whereas below the critical point of afterload, beneficial effects are predominantly manifested. These concepts derived from the existence of the critical point could explain the RV failure during LHB that is encountered clinically.

The decrease in the slope of the RV ESPVR is considered one of the reasons for such a reduction in RVSV at high afterload. In the underlying setting of increased RV volume, a compensatory increase in $\mathrm{RV}$ volume against high afterload cannot be expected, which may be another cause of the reduction in RVSV at high afterload. The decrease in the 


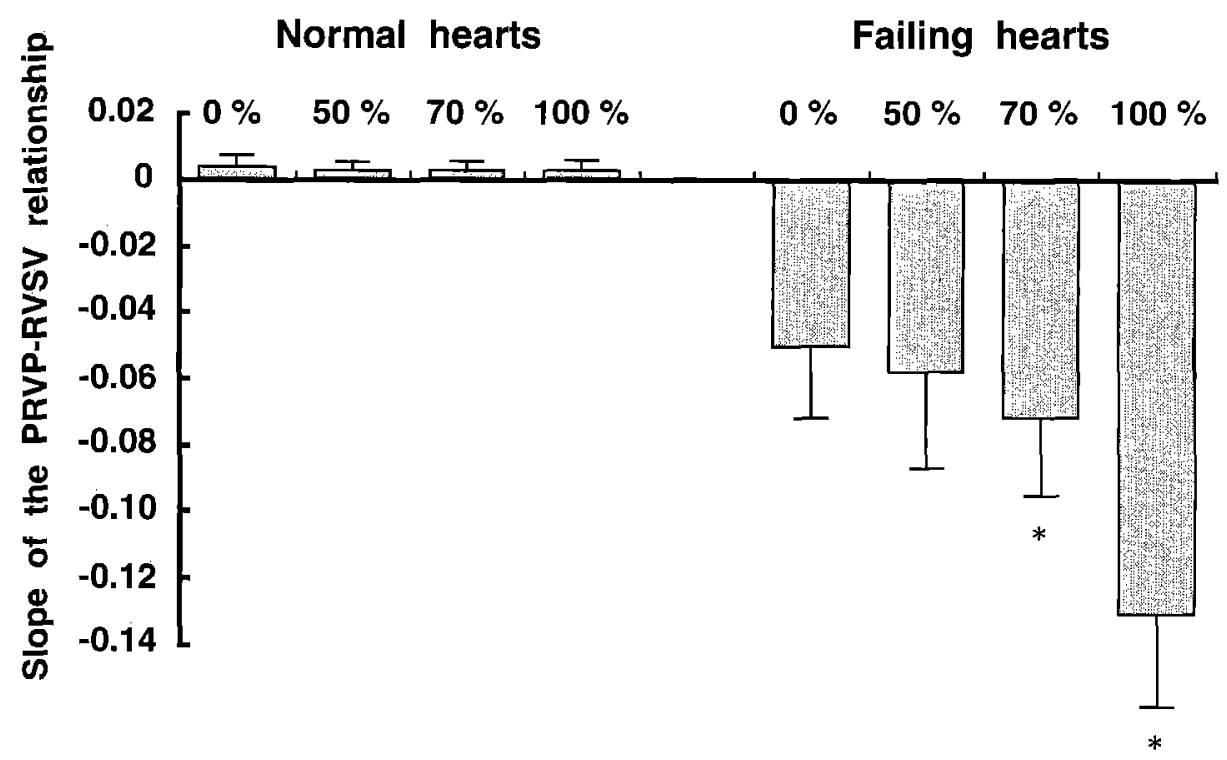

Fig. 5. Change in slope of PRVP-RVSV relationship with increases in assist ratio of LHB in both normal and failing hearts. ${ }^{*} p<0.05$ by Wilcoxon signed-rank test compared with values without LHB.

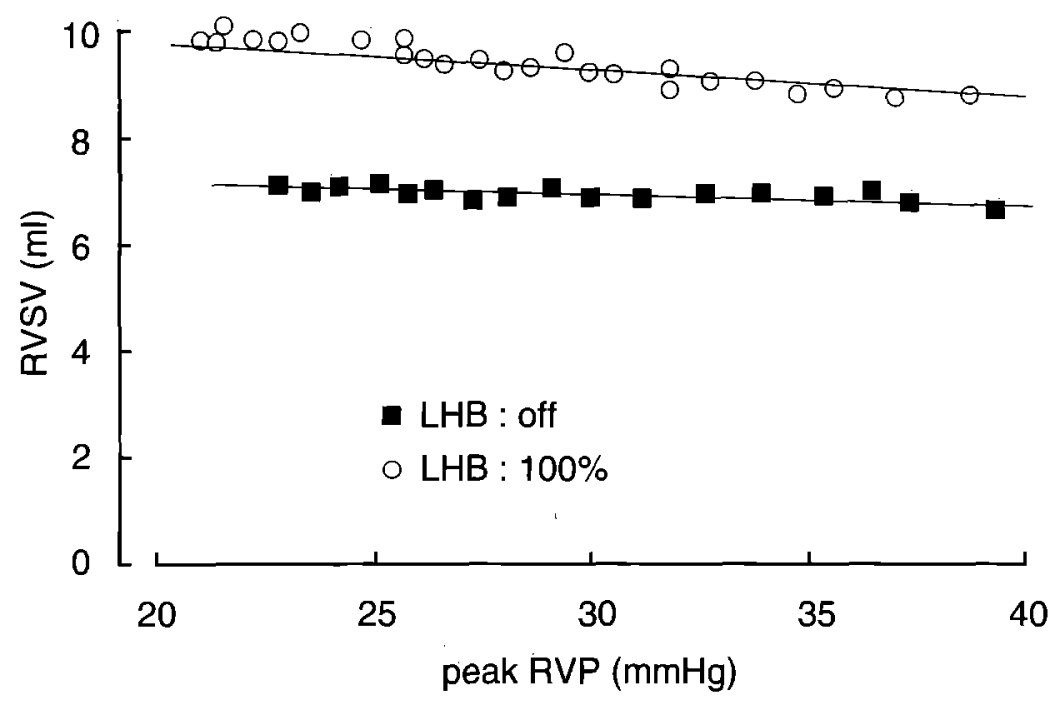

Fig. 6. Representative PRVP-RVSV relationship in normal hearts. RVSV was almost constant in normal hearts when afterload was increased regardless of assist ratio of LHB. Moreover, RVSV was maintained at higher level during LHB compared with that without LHB.

slope of ESPVR in combination with the increase in $\mathrm{RV}$ volume means impairment of RV contractility. Therefore such a reduction in RVSV during LHB was observed in failing hearts at the level above the critical point of afterload. However, in normal hearts with a relatively small RV volume even during LHB, RVSV was almost constant irrespective of RV afterload, because there was room for compensatory increases in RV volume in response to changes in afterload. Thus RVSV was maintained in normal hearts even against high afterload. Moreover, a significant increase in pulmonary artery flow and the absence of change in the slope of the PRVP-RVSV relationship during LHB were considered to contribute to the outcome that RVSV against varying afterload was maintained at a higher level during LHB compared with that without LHB.

To simulate the clinical conditions of heart fail- 

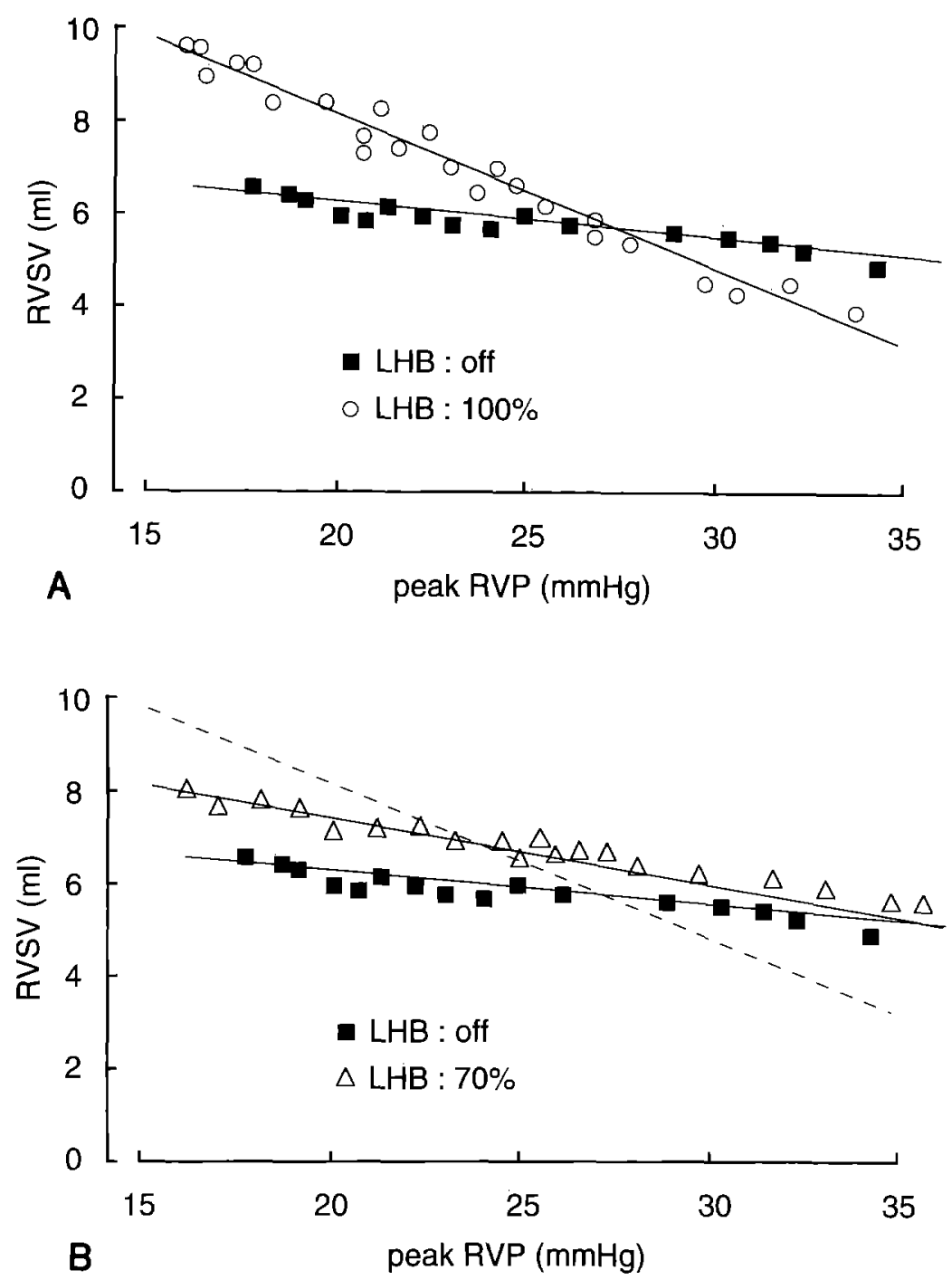

Fig. 7. A, Representative PRVP-RVSV relationship in failing hearts. Correlation between PRVP and RVSV was inversely linear with significant regression. Slope of correlation became steeper during $100 \%$ LHB compared with that without LHB. Intersection of two slopes (that is, "critical point") was noted. B, Reducing LHB assist ratio to $70 \%$ caused slope of PRVP-RVSV correlation to become more gentle, and thereby "critical point" shifted rightward, indicating higher afterload.

ure, a model of postischemic heart damage ${ }^{26}$ was used in our study. With this model, a significant decrease in RV contractility, a significant increase in RVEDV, and a significant elevation of RV enddiastolic pressure were noted compared with values in normal hearts. Changes in all of these RV hemodynamic variables were similar to those found in the study of Chow and Farrar ${ }^{18}$ which used congestive heart failure models produced by rapid ventricular pacing. Moreover, changes in these RV hemodynamic variables were similar to those ob- served in patients with chronic heart failure. ${ }^{33} \mathrm{Al}$ though there can be no assurance that the model of postischemic heart damage is representative of congestive heart failure, this model was considered comparable to other methods of producing heart failure for the understanding of RV function during LHB in patients with impaired RV function.

The common clinical situation that necessitates LHB is one of left ventricular failure with close to normal RV function, when RV function is well maintained by LHB even with higher levels of RV 
afterload, as this study demonstrated. However, in clinical situations, it is important to know how to cope with RV failure, inasmuch as this is one of the most important predictors of the prognosis in patients with LHB $^{1-8}$ In this study, reducing the assist ratio of LHB caused the slope of the PRVP-RVSV correlation to become more gentle and induced a rightward shift (that is, higher afterload) in the critical point. Therefore RV function against afterload was considered better tolerated when the LHB assist ratio was reduced. This suggests that reducing the LHB assist ratio may improve the tolerance of RV function against afterload with a rightward shift in the critical point, especially if LHB had been driven above the critical point.

Clinical conditions wherein the critical point is exceeded include underlying pulmonary obstructive disease, hypoxia, massive blood transfusion, and overdose of inotropic agents via a central vein. When LHB is driven above the critical point of afterload after maximum efforts to reduce pulmonary arterial resistance (for example, with vasodilating drugs or inhaled nitric oxide ${ }^{34}$ ), 100\% LHB cannot be expected to improve net RV function. Although it is common practice to infuse a fluid overload to cope with these situations, ${ }^{6,34}$ this approach to management induces an additional volume load in failing hearts that already have an increased RV volume. Inotropic agents can also be used to support RV failure. However, inotropic agents have the adverse effect of increasing pulmonary vascular resistance, especially if such agents are administered via a central vein. If all these medical strategies do not improve RV function, the reduction in the assist ratio of LHB may be recommended in clinical practice to improve the tolerance of $\mathrm{RV}$ function against afterload, as long as the LHB flow continues to meet the general metabolic requirements. Moreover, reducing the assist ratio of LHB may also facilitate RV functional recovery by reducing RV muscle tension with decreases in RV volume. As a matter of course, RV assist should be considered if reductions in assist flow fail to improve RV performance.

Although the accuracy of measuring left ventricular volume with use of a conductance catheter has been studied previously, ${ }^{20,21,35}$ the usefulness of this technique for measuring RV volume has not been clarified. However, McKay and colleagues ${ }^{36}$ and Solda and associates ${ }^{37}$ reported that the conductance catheter was reliable in monitoring relative change in RV instantaneous volume in vivo. We also found in our study that changes in RV volume measured by conductance catheter showed a significant correlation with changes measured by an electromagnetic flow probe both during LHB and without LHB. ${ }^{38}$ In addition, the high linearity of the slope of the RV ESPVR in this study suggests that $R V$ volume measured by the conductance catheter can accurately reflect relative changes in RV volume. Thus the relationships obtained by measuring relative change in $\mathrm{RV}$ volume by the conductance catheter technique may be acceptable for assessing the differences in RV function in individual cases, as McKay and colleagues ${ }^{36}$ and Solda and associates ${ }^{37}$ have reported.

In conclusion, this study demonstrates that LHB results in a net improvement in RV function in both normal and failing hearts at a physiologic range of afterload and that RV performance against afterload, however, is impaired by $100 \%$ assist of LHB in failing hearts. Moreover, this study shows that the intolerance against afterload in failing hearts may explain the RV failure during LHB that is encountered clinically.

\section{REFERENCES}

1. Bernhard WF, Berger RL, Stetz JP, et al. Temporary left ventricular bypass: factors affecting patients' survival. Circulation 1979;60(Suppl):I131-41.

2. Pae WE, Rosenberg G, Donachy JH. Mechanical circulatory assistance for postoperative cardiogenic shock: a three year experience. Trans Am Soc Artif Intern Organs 1980;26:25661.

3. Richenbacher WE, Pierce WS. Right ventricular failure following implantation of a left ventricular assist device. Curr Surg 1983;40:274-7.

4. Pennock JL, Pierce WS, Wisman CB, Bull AP, Waldhausen JA. Survival and complications following ventricular assist pumping for cardiogenic shock. Ann Surg 1983;198:469-78.

5. Pennington DG, Merjavy JP, Swartz MT, et al. The importance of biventricular failure in patients with postoperative cardiogenic shock. Ann Thorac Surg 1985;39:16-26.

6. Farrar DJ, Compton PG, Hershon JJ, Fonger JD, Hill JD. Right heart interaction with the mechanically assisted left heart. World J Surg 1985;9:89-102.

7. Parascandola SA, Pae WE, Davis PK, Miller CA, Pierce WS Waldhausen JA. Determinants of survival in patients with ventricular assist devices. Trans Am Soc Artif Intern Organs 1988;36:222-8.

8. Kormos RL, Borovetz HS, Gasior T, et al. Experience with univentricular support in mortally ill cardiac țransplant candidates. Ann Thorac Surg 1990;49:261-72.

9. Miyamoto AT, Tanaka S, Matloff JM. Right ventricular function during left heart bypass. J Thorac Cardiovasc Surg 1983;85:49-53.

10. Farrar DJ, Compton PG, Dajee H, Fonger JD, Hịl JD. Right heart function during left heart assist and the effects of volume loading in a canine preparation. Circulation 1984;4:708-16. 
11. Farrar DJ, Compton PG, Hershon JJ, Fonger JD, Hill JD. Right ventricular pressure-dimension relationship during left ventricular assistance in dogs. Trans Am Soc Artif Intern Organs 1984;30:121-3.

12. Yada I, Wei CM, Hattori R. Right ventricular function during left heart bypass evaluated by two-dimensional echocardiography. Trans Am Soc Artif Intern Organs 1985;31: 17-9.

13. Farrar DJ, Compton PG, Verderber A, Hill JD. Right ventricular end-systolic pressure-dimension relationship during left ventricular bypass in anesthetized pigs. Trans Am Soc Artif Intern Organs 1986;32:278-81.

14. Chow E, Farrar DJ. Effect of left ventricular pressure reductions on right ventricular systolic performance. Am J Physiol 1989;257:H1878-85.

15. Fukamachi K, Asou T, Nakamura Y, et al. Effects of left heart bypass on right ventricular performance. J Thorac Cardiovasc Surg 1990;99:725-34.

16. Elbeery JR, Owen CH, Savitt MA, et al. Effects of ventricular assist device on right ventricular function. J Thorac Cardiovasc Surg 1990;99:809-16.

17. Miyamoto AT, Matloff JM. Effects of left heart assist on right ventricular function. Artif Organs 1991;14(suppl 4):7-9.

18. Chow E, Farrar DJ. Right heart function during prosthetic left ventricular assistance in a porcine model of congestive heart failure. J Thorac Cardiovasc Surg 1992;104:569-78.

19. Moon MR, Castro LJ, DeAnda A, et al. Right ventricular dynamics during left ventricular assistance in closed-chest dogs. Ann Thorac Surg 1993;56:54-67.

20. Baan J, Jong TTA, Kerkhof $P$, et al. Continuous stroke volume and cardiac output from intraventricular dimensions obtained with impedance catheter. Cardiovasc Res 1981;15:328-34.

21. Baan J, Van der Velde $E$, de Bruin $H$, et al. Continuous measurement of left ventricular volume in animals and man by conductance catheter. Circulation 1984;70:812-23.

22. Suga H, Sagawa K, Shoukas AA. Load independence of the instantaneous pressure-volume ratio of canine left ventricle and effects of epinephrine and heart rate on the ratio. Circ Res 1973;32:314-22.

23. Suga H, Sagawa K. Instantaneous pressure-volume relationships and their ratio in the excised, supported canine left ventricle. Circ Res 1974;35:117-26.

24. Sagawa K, Suga H, Shoukas AA, Bakalar KM. End-systolic pressure/volume ratio: a new index of ventricular contractility. Am J Cardiol 1977;40:748-53.

25. Ross J Jr, Covell JW, Sonnenblick EH, Braunwald E. Contractile state of heart characterized by force-velocity relation- ship in variably afterloaded and isovolumic beats. Circ Res 1966;18:149-63.

26. James JM III, Gray LP, Charles EM, David RS, Lacques PG, Andrew SW. Quantification of the contractile response to injury: assessment of the work-length relationship in the intact heart. Circulation 1984;70:812-23.

27. Kass DA, Maughan WL, Guo ZM, Kono A, Sunagawa K, Sagawa K. Comparative influence of load versus inotropic states on indexes of ventricular contractility: experimental and theoretical analysis based on pressure-volume relationships. Circulation 1987;76:1422-36.

28. Park CH, Nishimura K, Kitano M, Okamoto Y, Ban T. Right ventricular performance is impaired by full assist of left heart bypass. Trans Am Soc Artif Intern Organs 1994;40:M303-8.

29. Park CH, Kitano M, Nishimura K, Okamoto Y, Ban T. Effect of left heart bypass on right ventricular function. Jpn J Artif Organs 1994;23:76-81.

30. Ross J Jr. Afterload mismatch and preload reserve: a conceptional framework for the analysis of ventricular function. Prog Cardiovasc Dis 1976;18:255-64.

31. Ross J Jr. Cardiac function and myocardial contractility: a perspective. J Am Coll Cardiol 1983;1:52-62.

32. Morita S, Kormos RL, Mandarino WA, et al. Right ventricular/arterial coupling in the patient with left ventricular assistance. Circulation 1992;86(Suppl):II316-25.

33. Katz AM. Cardiomyoplasty of overload: a major determinant of prognosis in congestive heart failure. N Engl J Med 1990;322:100-10.

34. Nose $Y$. Is it essential to implant a right ventricular assist pump for right heart failure in LVAD patients? Artif Organs 1995;19:287-8.

35. Burkhoff D, Van der Ve E, Kass D, Baan J, Maughan WL, Sagawa K. Accuracy of volume measurement by conductance catheter in isolated, ejecting canine hearts. Circulation 1985; 72:440-7.

36. McKay RG, Spears JR, Aroesty JM, et al. Instantaneous measurement of left and right ventricular stroke volume and pressure-volume relationships with an impedance catheter. Circulation 1984;69:703-10.

37. Solda PL, Pantaleo P, Perlini S, Finardi G, Pinsky MR, Bernardi L. Continuous monitoring of right ventricular volume changes using a conductance catheter in the rabbit. $\mathbf{J}$ Appl Physiol 1992;73:1770-5.

38. Kitano M, Nishimura K, Park CH, Okamoto Y, Ban T. Right ventricular function evaluated by volumetric analysis during left heart bypass in a canine model of postischemic cardiac dysfunction. J Thorac Cardiovasc Surg 1995;109:796-803. 